\title{
Will You Pass Me the Salt?
}

\author{
Salvador S. Coelho ${ }^{1}$ \\ 1 Portugal \\ Homœopathic Links 2015;28(4):230-233.
}

Address for correspondence Salvador S. Coelho, MD, Rua Antonio Nobre, 10 2795-021 Linda a Velha, Portugal

(e-mail: coelho.salvador@gmail.com).

\begin{abstract}
Keywords

- society pathology

- Natrum muriaticum

- cycles and segments

In this article the author points out the existing correspondence between a homeopathic remedy picture and a society's pathology. So to say societies can function in the wavelength of a certain homeopathic remedy. That is the case of Thailand, Brazil and California with a lot of Medorrhinum features-Germany that reminds Nux vomica picture, the Islamic State with so many Veratrum album characteristics and Portugal a typical Natrum muriaticum society. Many features of the people from this country stand for Natrum muriaticum like fate, grief, longing, concernment about appearances, high morals, sadness/depression, loss of love, bereavement, separation, perfectionism, low sexuality, addiction to giving, sympathy, desire to help others, being easily hurt, fixation upon past unhappiness, sentimentality, hospitality, love for books and music. The technique of cycles and segments is a powerful diagnostic technique routinely taught to students of the New England School of Homeopathy. Natrum muriaticum cycle is put on view and two clinical cases are shown.
\end{abstract}

One of the most interesting and creative articles of the European Journal of Classical Homeopathy was written by Zafiriou entitled 'Aurum Metallicum: The Key to the Solution of the Japanese Enigma'. ${ }^{1}$ He demonstrates to have a profound knowledge of the Japanese society and history as well as deep understanding of Aurum picture. A remedy so useful and so often indicated mainly in mental diseases.

However, what is most outstanding is that this author points out the existing correspondence between a homeopathic remedy picture and a society's pathology. Can societies function on the wavelength of a certain homeopathic remedy? I really think they do! According to the 'Social Organism Theories,' human societies are living organisms in the full sense of the word.

Zafiriou tells us also that William Ogburn, an American sociologist, believed that the ability of a civilisation to grow and evolve was related to the community's ability to adjust to the continuously changing conditions. This is also true for individuals. Finally Z. Novikov Lilinfeld believed that a society is exactly the same thing as a real organism.

Being such a frequent traveller, having visited at least 40 different countries, I have noticed societies so related to pleasure and joy of living, on the wavelength of Medorrhinum, like Thailand, Brazil and California. Societies so work oriented, fastidious, powerful and ambitious like Germany-where I lived for some time-that reminds me so much of the Nux vomica picture. The keywords of Veratrum album being: dogmatism, paranoia, strong morality and martyrs ${ }^{2}$; who can deny that the Islamic State does not need bombs but increasing doses of this remedy.

The society where I am living now is a typical Natrum muriaticum society. Portugal's national song Fado, now world's heritage, whose lyrics talk mainly about fate, grief and longing (saudade) is a best seller for Natrum muriaticum people. Our most respected Diva, Amalia Rodrigues, is a typical Natrum muriaticum woman that I perceived after reading the biography of this beautiful talented singer by Louro. $^{3}$ Truly a lot of our women need some salt (and some men too).

Bailey states in his book ${ }^{4}$ that this remedy is a reflection of the suppressed emotional pain that is engendered by the average upbringing in today's society, and also once man becomes civilised, he becomes unnatural. He is expected to adhere to certain codes of behaviour, irrespective of how he is feeling, and there are severe punishments for failing to do so. He learns to suppress his feelings, and to give appearances
DOI http://dx.doi.org/ $10.1055 / \mathrm{s}-0035-1566239$. ISSN 1019-2050. 
more and more importance. He loses touch with his loved ones and gives more time to winning prestige, respect and safety.

The concernment about appearances in our society is well elucidated in the adulteration of the old saying: 'Caesar's wife must be above suspicion'! Transformed into: 'Caesar's wife must look like above suspicion, if she is above suspicion, much better'!

High morals it is a typical Natrum muriaticum feature and we have this in our society what in my opinion is not bad because morality for me is not a code of ethics imposed by a cosmic dictator to control us, but merely rules that allow us to live together in society.

Depression is an important issue here. Portugal is one of the countries where the consumption of antidepressants per capita is greater. This depression is usually silent, with suicidal thoughts and mainly due to loss of love, bereavement, separation, estrangement from a loved one and the last but not the least suppressing sadness.

Perfectionism is a Natrum muriaticum feature and easy to spot here. This trait is, according to Macedo's recent book, ${ }^{5}$ an important risk factor for more deep mental pathology like depression, obsessive compulsive disorder, mental anorexia, anxiety and even sleep disorders.

Sexuality is also important. Natrum muriaticum is generally associated to low libido. I do not know studies that confirm this in our population, but what I perceive is generally Portuguese women do not feel physically attracted to a man until they love him, they enjoy sex so long it is loving and sometimes they are unable to experience orgasm even with a loving partner. All are characteristics of Natrum muriaticum according to Dr. Bailey. In a well-balanced relationship love should be the nourishment and sex the seasoning. When sex becomes the nourishment, it can happen what the rock group Floyd sings in one of its songs: 'Oh! Day after day love turns gray'. ${ }^{6}$ Love actually is not a women's invention, to the despair of some men, but the most powerful, beautiful and rewarding characteristic of the Creator. 'Love is the light scaring darkness away. ${ }^{7}$

Some more Natrum muriaticum characteristics can be found amongst us Portuguese: addiction to giving, sympathy, helping other people, being so easily hurt, fixation upon past unhappiness, sentimentality and even hospitality.

Portuguese people not only buy books but also love to read them. This rubric can also be found in my favourite repertory. ${ }^{8}$

In classic homeopathy there are several diagnostic approaches to reach the Simillimum ('There are several ways to reach the mountain'). Naturally the most important thing is to give our patients the remedy they really need. The technique of cycles and segments is a powerful diagnostic technique developed by Herscu and routinely taught to students of the New England School of Homeopathy.

In this method every symptom a person expresses is an example of one of the fundamental segments operating in that person's cycle of disease. The cycle itself is a flow of events that is composed of several segments. Each segment flows into the next until you come full cycle again. The cycle is the disease. The pattern is a continuous flow. If we can look at the disease this way, we will be better able to identify the main elements or ideas (fundamental segments) within each of the remedies. ${ }^{9}$

So here is the Natrum muriaticum cycle:

1. Emotional vulnerability sensitivity.

2. They want to close off and protect themselves, from other people.

3. Too close, hard, tough and dry and so on.

4. They have a kind of cracking when opening up.

5. Discharge, hay fevers.

6. The fragility and weakness and they turn to segment 1 again.

\section{Case 1 (My First Case, My First Prescription- 1995)}

Woman, 46 years old, nurse, born in Bragança, living in Casal Cambra, married, ex-smoker. She came to my practice for treatment of hay fever.

Since she was aged 20 years, she was complaining of sneezing, nasal itching, obstruction and bland discharge. Her symptoms were more frequent in winter and spring. She had more symptoms:

- Pulsating parietal headaches

- Itching in her inside ears, eyes, throat and skin

- For the previous 3 years bouts of cough, with mucous sputum, but no wheezing or shortness of breath

- Depression when she was 40, again at 43 and then after her mother-in-law passed away (at 46 years of age)

She craves fish and loves the seashore that makes her feel much better.

Concerning her past history, she had Kala Azar (leishmaniasis or black fever) at 6 years of age and Asian flu at 10 years.

Family history: her father had alcoholism and her mother died at 56 years.

\section{Analysis}

With no homeopathic software help at that time, I had to resort to the repertory. ${ }^{8}$ I took just five characteristic symptoms:

- MIND, ailments from grief

- MIND, ailments from death of loved ones or friends

- MIND, depression after grief

- GENERALS, seashore ameliorates

- FOOD, desires fish

Six main remedies showed up: aur, carc, ign, nat-m, ph-ac and staph (-Fig. 1)

I prescribed in the middle of January 1995 a first dose of Nat-m 30CH and a second one in the end of March.

\section{Follow-up}

She had her follow-up interview in May. She was much better psychologically, her hay fever improved markedly and her cough disappeared completely but came up again in the last 2 days when the weather got humid. So I gave her a single dose of Nat-m 200CH.

A few months later I saw her again for sleeplessness, and after taking the case, I prescribed Calcarea carbonica $30 \mathrm{CH}$, 


\section{Dr. S. Saldanha Coelho (25336)}

Nurse: Hay fever

Soma de sintoma (/graus)

Este análise contem 121 medicamentos e 5 sintomas. Intensidade é considerada

\begin{tabular}{|l|l|l|}
\hline 1. MIND - AILMENTS FROM - grief & 1 & 90 \\
\hline 2. MIND - AILMENTS FROM - death of loved ones & 1 & 21 \\
\hline 3. MIND - SADNESS - grief, after & 1 & 13 \\
\hline 4. GENERALS - AIR - seaside; air at the - amel. & 1 & 24 \\
\hline 5. GENERALS - FOOD and DRINKS - fish - desire & 1 & 31 \\
\hline
\end{tabular}

\begin{tabular}{|c|c|c|c|c|c|c|c|c|c|c|c|c|c|c|c|c|c|c|c|c|c|c|}
\hline \multirow{2}{*}{\multicolumn{2}{|c|}{$\begin{array}{c}1 \\
\text { carc } \\
5 / 6\end{array}$}} & 2 & $\begin{array}{l}3 \\
\mathrm{mbr}\end{array}$ & $\begin{array}{c}4 \\
\text { con }\end{array}$ & $\begin{array}{l}5 \\
-\mathrm{m}\end{array}$ & $\begin{array}{l}6 \\
\text { aust }\end{array}$ & $\begin{array}{l}7 \\
\text { at-s }\end{array}$ & $\begin{array}{c}8 \\
\text { ign. }\end{array}$ & $\begin{array}{c}9 \\
\text { oh-ac }\end{array}$ & 10 & $\begin{array}{l}11 \\
\mathrm{dr}-\mathrm{m}\end{array}$ & $\begin{array}{c}12 \\
\text { verat. }\end{array}$ & $\begin{array}{l}13 \\
\text { ach. }\end{array}$ & $\begin{array}{c}14 \\
\text { aur. }\end{array}$ & $\begin{array}{l}15 \\
\text { op. }\end{array}$ & $\begin{array}{l}16 \\
\text { ars. }\end{array}$ & $\begin{array}{c}17 \\
\text { rali-br }\end{array}$ & 18 & $\begin{array}{c}19 \\
\text { hos. }\end{array}$ & 20 & $\begin{array}{c}21 \\
\text { alc-p }\end{array}$ & $\begin{array}{c}22 \\
\text { gels. }\end{array}$ \\
\hline & & $4 / 10$ & $4 / 7$ & $4 / 6$ & $4 / 6$ & $4 / 6$ & $4 / 4$ & $3 / 9$ & $3 / 8$ & $3 / 7$ & $3 / 3$ & $3 / 3$ & $2 / 6$ & $2 / 5$ & $2 / 5$ & $2 / 4$ & $2 / 4$ & $2 / 4$ & $2 / 4$ & $2 / 3$ & $2 / 3$ & $2 / 3$ \\
\hline . & 1 & 4 & 3 & 1 & 2 & 3 & 1 & 4 & 3 & 3 & 1 & 1 & 3 & 3 & 2 & 1 & 2 & - & 3 & 2 & 2 & 2 \\
\hline 2. & 1 & - & 2 & 3 & - & 1 & 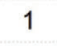 & 3 & 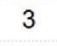 & 3 & 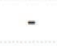 & . & 3 & - & 3 & 3 & 2 & - & - & - & - & 1 \\
\hline 3. & 1 & 2 & - & - & 2 & 1 & 1 & 2 & 2 & 1 & 1 & - & - & 2 & - & - & - & - & - & - & - & - \\
\hline 4. & 2 & 2 & 1 & 1 & 1 & - & 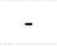 & - & - & 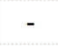 & 1 & 1 & - & - & - & - & - & 2 & - & 1 & - & - \\
\hline 5. & 1 & 2 & 1 & 1 & 1 & 1 & 1 & - & 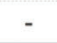 & & & - & - & - & - & - & - & 2 & 1 & - & 1 & - \\
\hline
\end{tabular}

Fig. 1 Repertorization Case 1 (Murphy's Reportory in Radar).

three single doses. She improved so much to the point of stopping the allopathic sedatives.

One year later I saw her at the hospital where I practise and she was still well.

In July 2015 I called her and she told me she had been well for 15 years, free from hay fever symptoms.

\section{Case 2 (2002)}

Woman, 32 years old, children educator, born in Lisbon, smoker, single.

The woman came to hospital for treatment of hay fever she had suffered from since 1986 when she was 16 years. She underwent allopathic immunotherapy for house dust mites but with poor improvement.

In March 2002 she was complaining of coryza, nasal itching, obstruction and sneezing. Wet weather made her worse, but seashore improved her. Other symptoms:

- Bouts of dry cough and wheezing mainly at night

- Sporadic irregular palpitations

- Headaches since her daughter was born, mainly on waking, more frontal and parietal. Even sleep did not make her better

- Acne

- Moderate anxiety and depression mainly when she and her male friend separated from each other 5 years before

- Crying when alone, better by consolation

- She did not watch TV because she was very sensitive to human suffering

- She had sleeplessness, nightmares concerning violence, being pursued, aircraft falling and woke up fearful after those nightmares

- Low blood pressure

She was warm blooded, had low thirst and craved fruit, bread, fish and coffee.
After I analysed the case with the Repertory mentioned above, Natrum muriaticum showed up as main remedy (-Fig. 2). I prescribed one daily dose of Nat-m $5 \mathrm{CH}$ for 10 days and a single $30 \mathrm{CH}$ dose 1 month later.

\section{Follow-up}

She came up in May 2002. She had no more hay fever complaints or headaches, but she was still having palpitations when she was stressed.

She had another follow-up in September 2002. She was having a lot of work and stress. No more nasal symptoms, palpitations or headaches. Light irritability and sadness during menses. Still having nightmares and dwelling on past disagreeable occurrences.

One year after (September 2003) she was still free from hay fever but came for intense cough after a cold. Nocturnal cough related to lying down also. Light wheezing. She was still smoking and drinking coffee. Nightmares, palpitations, sadness before menses, low thirst and heat intolerance persisted.

I gave her another dose of Nat-m 30CH. She did not come again to another follow-up consultation.

\section{Discussion}

I believe that both patients I have presented were not Natrum muriaticum constitutionally. The first was Calcarea carbonica and the second unfortunately did not give me the chance to discover because she was lost for further followup. I guess she would need Pulsatilla afterwards as constitutional remedy (frightful dreams, persistent dreams, low thirst, heat intolerance and consolation ameliorates). According to Anselmi ${ }^{10}$-that takes into consideration works of Gibson-Miller, Lathoud, Clark, Farrington and VannierPulsatilla is one of the remedies that follows well Natrum muriaticum. However, both needed Nat-m for their hay fever that actually solved it (to remove the outside layer). 


\section{Dr. S. Saldanha Coelho (25336)}

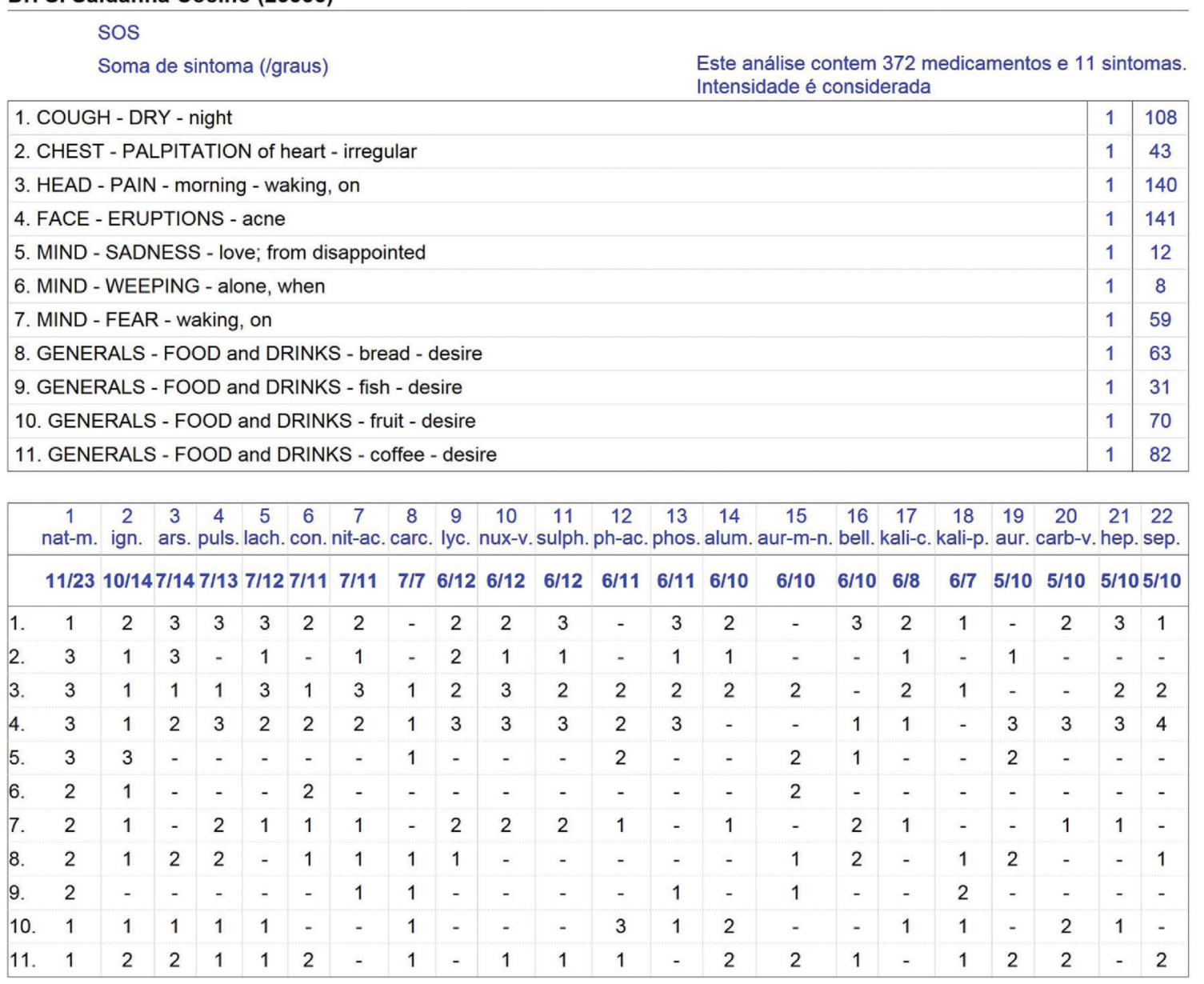

Fig. 2 Repertorization Case 2 (Murphy's Reportory in Radar).

One of the most complete pictures of the homeopathic therapeutics of hay fever was published by Herscu. ${ }^{11}$ As he says Natrum muriaticum is the remedy that is most frequently used in hay fever, or to put it differently, there are many people who need Natrum muriaticum who have a complaint of hay fever.

We all certainly agree that grief and humiliation are important features to lead people into a Natrum muriaticum state, although in Vermeulen's Materia Medica ${ }^{12}$ we cannot find both of them mentioned in causation-possibly an omission to be corrected.

\section{References}

1 Zafiriou V. Aurum metallicum: the key to the solution of the Japanese enigma. Eur J Classic Homeopathy, Alonissos 2006;2(8): 44-50
2 Vithoulkas G. The Paranoid Side of Veratrum Album. Alonissos, Greece: European Journal of Classical Homeopathy; 1996

3 Louro S. Amalia o Romance da sua Vida. Lisbon, Portugal: Saida de Emergência; 2012

4 Bailey P. Homeopathic Psychology. Berkeley, CA: North Atlantic Books; 1995;xx:175-222

5 Macedo A. Ser ou nao ser (perfeito)? Lidel Lisboa 2012;xx:75-162

6 Floyd P. The Wall: One of my tunes. EMI Records Ld.; 1979

7. Frankie Goes to Hollywood, Welcome to the Pleasuredome: The Power of Love (side 4). ZTT Records; 1984

8 Murphy R. Homeopathic Medical Repertory. Pagosa Springs, CO: Hahnemann Academy of North America; 1993

9 Herscu P. Stramonium, with an Introduction to Analysis Using Cycles and Segments. Amherst, MA: NESH Press; 1996

10 Anselmi E. Los Remedios Homeopaticos y sus Relationes. Buenos Aires; 1935

11 Herscu P. Herscu Letters 43 \& 44. Amherst, MA: New England School of Homeopathy; 1999

12 Vermeulen F. Concordant Materia Medica. Haarlem, The Netherlands: Emryss bv Publishers, Haarlem; 1997:1183 